\title{
The Four Pillars of Retirement
}

\author{
by Denis Kessler*
}

Many dramatic changes have taken place since World War Two as far as old age is concerned. Old age was associated with poverty and senility, it is no longer the case. People aged 60 years old and over enjoy today the highest relative level of living in the modern history of European industrialized countries. Recent available data show clearly that the level of living of aged people (expressed in unit of consumption) lies above the average level of living of the whole population, certainly well above the level of living of young adults. Let us note however that it is true that there are still inequalities among aged people and that this picture does not look as favourable everywhere.

This note will proceed as follows: we will first briefly present the four pillars of retirement (Part 1), evoke the possible end of the golden age or retirement (Part 2), assess the future of retirement (Part 3), and advocate the promotion of the third and fourth pillar (Part 4).

\section{The four pillars of retirement}

The level of living of aged people may be seen as the combined result of various phenomena. Their level of well being rests upon four pillars. Let us briefly evoke how these pillars have evolved throughout the last forty years to understand the current situation of the elderly.

\subsection{First pillar: the basic old age social security scheme}

Public transfers through pay-as-you-go social security schemes have increased at a very fast pace since their implementation. The elasticity of public transfers to national income lies well above unity which means that each time the GDP was growing by $1 \%$, public transfers benefitting the elderly were growing 2 or even $3 \%$. Public transfers represent therefore a steadily increasing share of national income. The demographic ratio (people aged more than 60 or 65 over people aged 20 to 60 or 65 ) as well as the dependency ratio (retirees over contributors) favoured throughout the last 40 years the increase of public transfers to

\footnotetext{
* Deputy Secretary General of the Geneva Association
} 
the elderly. The post-war period was marked by the extension of this basic old age coverage to the population as a whole, by the increase of replacement rates (ratio of the pension to the last employment income) and by the reevaluation of benefits (that were often overindexed.).

\subsection{Second pillar: the private pension schemes}

Private pensions expanded also very quickly over the same period. The marked development of vocational retirement schemes reflected a convergence of interests of both social partners, corporate as well as workers unions. Most of these schemes operate under the funding principle but in certain countries such as France, they operate according to the payas-you-go principle. The level of coverage increased steadily for the last 40 years.

\subsection{Third pillar: personal saving and private insurance}

Personal saving increased in all European countries from the 50's to the middle of the 70 's. Let us recall that a large number of cohorts being retired today have been able to accumulate wealth throughout their lifetimes, thanks to rising real incomes, a large access to credit markets, the importance of capital gains. Today's retirees hold rather large amount of assets due to their saving behaviour over their life cycle. It is true that the household savings rate has decreased since 1975 in most European countries but this trend is due primarily to the young cohorts financial behaviour.

\subsection{Fourth pillar: labour force participation of the elderly}

Labor force participation rates of the aged have fallen dramatically throughout the last 40 years. This trend was often encouraged by governments and firms taking measures to bring about early retirement, and has accelerated since the rise in unemployment in the mid 70 's. The consequence of this phenomenon is that the share of labour income in aged people total resources has been reduced to less than one fifth.

To be complete, one should also mention a possible fifth pillar of retirement, that is to say private intergenerational transfers benefitting the elderly. But as a matter of fact, it seems that those private intergenerational transfers have changed of sign. There is some evidence that before the creation of public pension schemes, the young generations were helping the old ones in transfering voluntarily some resources. It seems that today private intergenerational transfers go the other way and benefit the young generations. The increase in bequests and inheritances shows that the aged compensate partly the burden imposed on the young generations by the public schemes by transfering resources backwards. This is therefore no longer a pillar, even if it could become one again in the future.

\section{The end of the golden age of retirement?}

Thanks to the three first pillars, and especially to the first one, we live in the "golden age" of retirement. The aged enjoy very high relative economic and social status in our societies. They are able to consume plenty of a very rare good: leisure. Due to the increase of life expectancy and the lowering of actual retirement ages, the retirement period 
represents one fifth to one fourth of total lifetime. The aged also benefit from incomes that are more steady than those of active workers and often inflation-proof.

Is this state of bliss likely to last for ever? Are the existing cohorts of adults going to enjoy a similar status when they will reach retirement in 20 ou 25 years from now on? Will today's workers follow the same life course as the one followed historically by today's retirees? To try to answer these questions, we will briefly indicate some elements to be taken into account when exploring the long term, the future.

\subsection{A feeling of latent worry}

The future of old age insurance schemes is causing increasingly marked concern. A growing number of observers and households are asking about the future viability of pension systems. A growing number of studies explore the adverse effects that those schemes may have on savings and capital accumulation, work effort, and even fertility.

A feeling of latent worry is perceptible. Will pension and social security be able to keep to their explicit or implicit commitments and guarantee sufficient resources to the elderly? An household survey carried in some European countries reveals clearly that Europeans appear to be pessimistic. More than half of them consider that tomorrow's pensions will lose their purchasing power compared to today's pensions. It seems clear to an ever increasing number of people that these schemes will face difficulties in the years to come. These misgivings, which are largely justified, are based on estimates of an unfavourable demographic evolution as a result of birth rate levels which will not permit population replacement. They are also the result of a bleack economic outlook, characterized by a slow resorption of unemployment and a practical standstill of real income. It therefore looks as if the "golden age" for retired people has come to a close, even if the real difficulties will not be apparent for another ten years or so.

However, part of the current uneasiness is also caused by the fact that no-one knows how the retirement system will adapt itself to the aforementioned new economic and demographic conditions.

\subsection{The possible adaptations of the four pillars}

Although many scenarios have been proposed, the actual film that will be produced is still very much in the dark. Four main possibilities can be outlined:

(1) continuance in force of practically all the provisions of the current system (age at which the social security entitlement begins, rate of replacement...). This would result in an exceptionally heavy burden on the social transfers effected by the first pillar (and also by the second pillar when it functions on the basis of pay-as-you-go) to the advantage of tomorrow's retirees, but to the disadvantage of the actively employed generations of tomorrow; these are the numerically inferior children of the "baby boom" generation, who will be called upon to support the full burden of anticipated development;

(2) limitation of the increase in the total amount of pensions paid into by the first two pillars of the pension scheme through a relative reduction in individual contributions (reduction in the rate of remplacement or lower indices). The retired people of tomorrow, i. e. the actively employed of today, are therefore the ones who will suffer the consequences of the expected unfavourable evolution; 
(3) a significant increase in the pension age and elimination of measures which encourage early retirement. This measure would also be aimed at reducing social transfers benefitting older persons, by radically reversing the trend to quasi-elimination of labor incomes for older persons;

(4) a very sustained individual savings effort throughout the coming years, strongly encouraged by the Government, in order that the wealth thus accumulated as well as the income which it generates may alleviate any possible reduction in pensions paid out by the first pillar, or the less favourable character of the provisions governing retirement.

\subsection{Substitution and complementarity between the four pillars}

In this way, the transfers to be made in the future can lead to a restructuring of the various ways and means used to finance the period of retirement. The relative position of each of the four pillars may vary greatly depending on the final choice made. Taken together, these four pillars offer possibilities of partial substitution which should be taken into consideration, such as:

(1) a decision to increase greatly the pension age, as has been announced in the United States, will help to limit an increase in the first two pillars;

(2) if it is decided to increase the social transfers, in exchange for a substantial increase in contributions or taxation, people will feel less need for personal protection through savings;

(3) a decision to reduce the level of pensions, retaining the current provisions in respect of retirement should strongly favour a development of the third pillar and, to a lesser extent, the second pillar.

\section{Assessing the future of retirement}

Although it is possible to trace various possible means of adaptation for the overall system of financing people's retirement, as well as the consequences with respect to the relative place of each of these pillars, it is much more difficult to determine precisely which options will be taken by the respective industrialized countries. This uncertainty with regard to what solutions will be finally adopted in order to restructure the retirement system is also a cause for worry at the level of the individual family.

Certain factors influencing the future evolution of retirement systems appear to be fundamental:

(1) State budgetary restraints and the limits to taxation will determine Governments' amount of leeway in modifying the level of transfers (first pillar);

(2) the external constraints of the various countries affected by ageing. Contributions to retirement funds increase wage and salary levels and therefore production costs. Also, the necessity of meeting the challenge of competition may contribute to a slowing down of the development of the first and second pillars;

(3) the evolution of the labour market and in particular of the unemployment rate will determine the possibilities of increasing the retirement age and any changes concerning cessation of activity for older people (fourth pillar). Changes in long-term working conditions (lifetime jobs, seniority rules, continuing validity of employment contract clauses, etc.) will influence the supply and demand for work at higher age levels; 
(4) the evolution of the financial markets together with the evolution of inflation, will influence the development of retirement schemes functioning according to the funding principle (second pillar) as well as that of individual savings and personal insurance coverage (third pillar);

(5) changes in social relationships, which until now have tended to evolve in the direction of greater group protection against old age, will promote national and vocational solidarity rather than individual protection;

(6) changes in the economic and financial behaviour of households, which appear to be accelerating. Therefore, a vigorous effort to raise the level of wealth accumulation, a recovery of the birthrate, a new attitude towards employment and a slowing down of physical ageing are among the factors which, by modifying the pattern of life, can influence the evolution of the retirement system.

In order to identify the necessary changes to be made in retirement systems in industrialized countries, it is advisable to reflect on these various factors and on the effects which their development can have. In order to determine the best strategies to be followed in order to cope with economic and demographic changes, it will be necessary to have a precise understanding of the restructuring of the four pillars of retirement.

\section{Promoting the third and fourth pillars}

It seems necessary to stabilize the level of the first pillar (a difficult task since retirees are voters), and to better monitor the level of the second pillar. The policy to cope with the future difficulties should raise the levels of both the third and fourth pillars.

The policy in favour of the third pillar should be pursued and emphasized by taking measures promoting long term personal savings oriented towards the individual preparation of retirement. Care should be given to increase the global rate of savings of household, and not only to alter the structure of savings. Let us recall that the acceleration of household wealth accumulation has very positive economic effects by allowing a regular and sound financing of firms' investments.

But stabilising the first pillar, reforming the second pillar and promoting the third pillar will certainly not permit to overcome all the difficulties we will face in the future resulting from the ageing of the population and the perspectives of slow economic growth. The fourth pillar must also be promoted: how can the contribution of aged people to the economic and social life be increased? How can we make a better use of the capacities, knowledge and energy of aged persons? How can we better integrate aged persons in the social and economic life? To merely ensure the financing of consumption needs of aged persons is not enough: the ageing of the European population calls for a radical change in the way the elderly live in our society.

A greater contribution of the elderly to economic and social life should also be encouraged. If aged workers are more and more rare - and the decline in activity rates among aged is notably due to the development of social security and pension schemes - this trend could be reversed if a certain flexibility was again introduced in the way labor contracts end. But one must also consider unpaid work done by the elderly. They can provide private 
or family services not accounted for in the national accounts and not compensated by a wage. Services that aged persons can provide are numerous and one is struck by the fact that they are not really acknowledged. To consider aged persons as unproductive is wrong. The "balance sheet" of an aged person may be much more balanced than most people think.

\subsection{The importance of cohort effects}

Let us first underline that aged people of today are quite different from aged people of yesterday: each generation follows a quite different road from the one followed by previous generations:

(1) Today's retirees have known the Great Crisis, suffered from World War Two, actively participated in the European reconstruction afterwards (including demographic reconstruction), and ended their economic life again in an economic crisis marked by rising unemployment and the trend towards early retirement.

Tomorrow's aged people - today in the active part of their lives - will not have followed the same path, will not have suffered from a major war, but will have benefitted from the accumulation of previous generations and enjoyed a high quality of life, will have raised less children, will have work less and in better conditions. It seems obvious that the intellectual and physical abilities, the needs and desires of tomorrow's aged will differ markedly from today's retirees.

(2) The duration of retirement was limited until recently. Today, the upward shift of survival functions combined with the decrease in activity rates past age 55 have increased the duration of retirement and the mental and health status of aged persons has greatly improved with the introduction of social security and pension schemes.

(3) Labour market participation rates of women were low in the period following World War Two, but have since increased in most European countries. Projections show that the women's rates will be identical to men's at the beginning of the next century. This dramatic change will have strong effects on social security and pension schemes: women used to benefit from reverse pensions, they are now entitled to full pensions.

Such "vintage" or "cohorts effects" are numerous as most of the elements or factors shaping life cycles are changing. These changes will be favoured by the progressive shift towards the service economy. The way people produce is certainly one of the major element to take into account when explaining the way people live, work, retire, in other words, age.

But changes may take place at a slower pace than desired, notably because of the weight and inertia of social structures and organisations. If social security and pension schemes have been able to largely improve the collective and individual well being when they were introduced - they had become necessary by the development of the industrial economy - they may now, if nothing is done to make them evolve, prevent a quick recovery of European economies by slowing down the introduction of new ways to produce and exchange. 


\subsection{The development of the fourth pillar}

The development of the fourth pillar could be favoured by the following five measures.

(1) Long term planning of human resources. Firms often neglect the long term outlook of their hiring policy resulting in manpower age pyramids that are unbalanced, reflecting the business cycle. A stop-and-go policy concerning the hiring or firing of manpower leads to very irregular age pyramids, which may exert very adverse effects, (i. e. varying rates of promotion or varying flows of people retiring). One way to promote the fourth pillar is for firms to adopt a long term strategic management of human resources.

(2) Increasing the flexibility in careers. An increased career flexibility could tamper the importance of seniority rules with their steep age-income profile that makes aged workers (too) expensive in relation to their productivity. New packages of compensation could loosen the relationship between age and wage, and prevent that the aged are first on the firing list (or pushed in retirement) and last on the hiring list. The roots of the fourth pillar are to be found in the first stages of adulthood and active life. It would be an error to consider that the problem of aged people can be solved without introducing any change in the earlier stages of lifes.

(3) Loosening the relationship between age and hierarchical position. One of the characteristics of prevailing seniority rules is to introduce a rather tight relationship between age and the position held in an institution. Age pyramids and hierarchical pyramids are often identical, at least for executives and middle management. One way to act on the hierarchical structure is to have someone retiring. It is often the only way to organize a chain letter promotion mechanism. If an aging person could abandon his hierarchical position but stay in the same firm in another position (and possible with another wage), it would be possible to smoothen the retirement process.

(4) Multiplying community jobs. Aged people have abilities that could be used elsewhere than in the production process. There are indeed large areas of activity where the elderly could take part: Firms have also a social responsability and could help by partially financing jobs benefitting the entire community. In certain countries, firms have helped to promote associations of retirees that put their talents at the service of enterprise creation, economic development in LDC's, etc. These experiences are so far of a limited scope, but their development should be encouraged, notably in the area of professional training.

(5) Enlarging the role of social security and pension schemes. These schemes organize mainly a transfer of financial resources from the young to the aged. They have tended to replace the traditional relationships that existed in a firm or in a family between members of succeeding generations. These schemes should seek ways, and use some of their means in order to promote new types of relationships between retirees and active workers, between young and aged workers. They can contribute substantially to solve the problem of unemployment and to improve the functioning of the labour market. 
Other experiences and ideas could and should be mentioned, but the question remains why so little has been done until now to adapt our social schemes, our institutions, our laws, our rules, to the ageing of the European population. There seems to be a real inertia preventing the necessary adaptations to take place. Even a sound financing of the retirees will not be enough: if we want to avoid the enlargement of a generation gap - and possibly the apparition of a generation struggle - things will have to change.

\section{Conclusion}

The adaptation of our economic and social structures to the general ageing of the European population will certainly be more difficult than we think. Too many people - including policy makers - are shortsighted and do not take into account the long term perspectives. It is now time to adopt a farsighted attitude, take into account the utility of future generations and choose the track to be followed in the coming years, even if this choice may at first seem unpopular. Overcoming the difficulties that will appear at the beginning of the next millenium is certainly the highest challenge we all have to face. 